\title{
NUEVO APORTE AL TRATAMIENTO DE LA ALGOMENORREA
}

\author{
Dr. Alvaro Espinosa y Espinosa* \\ Dr. Herbert Wagner C.** \\ INSTITUTO COLOMBIANO DE SEGUROS SOCIALES \\ (CLINICA SAN PEDRO CLAVER) Bogotá - Colombia
}

\section{I - Introducción}

Las experiencias clínicas ginecológicas, nos demuestran que más de la mitad de las pacientes padecen de algomenorrea, variando los síntomas desde simples molestias físicas y mentales hasta intensos ataques dolorosos en las regiones lumbosacra y pelviana; $10 \%$ de ellos de tipo severo. Estos síntomas a pesar de su pronóstico benigno, no dejan de ser un problema en la consulta ginecológica y desde tiempos remotos se estudiaron infinidad de tratamientos para eliminar, o por lo menos mitigar este padecimiento.

Sobre todo desde el punto de vista laboral, la algomenorrea presenta

a) Premenstrual o congestiva

(inflamaciones, endometriosis)

b) Intramenstrual o espasmódica

(posiblemente psicógena)

Entendemos por primaria desde la menarquia o primer año de ella, y secundaria después del primer año de la menarquia.

En este trabajo se han descartado las lesiones orgánicas del aparato genital femenino. varias dificultades. La mayoría de las mujeres afectadas se ven obligadas a suspender periódicamente sus trabajos, en perjuicio tanto de ellas mismas como de la productividad de la empresa; y si durante estos días de padecimiento concurren a sus empleos, no producen una actividad normal, ya que psíquica y orgánicamente se encuentran impedidas.

Aceptamos la algomenorrea como un síntoma de menstruación dolorosa que supone el primer eslabón de un círculo vicioso que comienza por el espasmo, llega al dolor y vuelve al espasmo.

Clásicamente consideramos la algomenorrea dividida en dos clases:

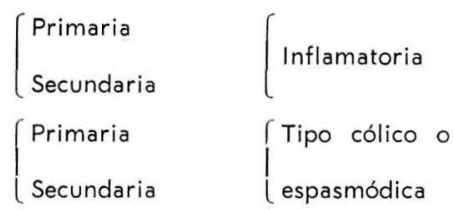

De acuerdo a su posible doble etiología, es evidente que el tratamiento

* Profesor Asociado de Ginecología y Obstetricia de la Universidad Nacional. Ginecólogo del I.C.S.S. de Bogotá.

** Médico Auxiliar de Ginecología del I.C.S. S. Instructor de la Clínica David Restrepo. 
debe ir dirigido sobre estas causas fundamentales: espasmo muscular, espasmo vascular y componente psicógeno.

\section{Interpretación del dolor, según diferentes tendencias}

Las ideas generales que presiden la hipótesis interpretativas de la génesis del dolor en la dismenorrea pueden ser clasificadas en tres grandes apartados:

A) Las contracciones uterinas son las responsables del dolor.

B) La anoxia uterina es el factor principal en la sensación dolorosa.

C) Una disregulación psicosomática es la que hace disminuir el umbral doloroso en la mujer dismenorreica.

A) Contracciones uterinas. Parece lógico admitir que si el órgano se contrae más intensamente, la sensación de la mujer sea de carácter doloroso. En lo que no hay acuerdo es en la causa primordial de esa hipercontractilidad uterina: tono elevado, hipersensibilidad de receptores de estímulos, alteraciones neuríticas de los nervios simpáticos uterinos, producción de "menotoxinas", anormalidad de la ordenación contráctil, estrechez orgánica $\bigcirc$ espasmódica del cuello, coágulos intrauterinos, asociación de hipercontractilidad con desequilibrios psicosomáticos o neurovegetativos, o finalmente, como quiere Seguy (1959), un conglomerado de factores caracterizado por:

a) Hipersimpaticotomía con hipersensibilidad simpática.

b) Anoxia, como consecuencia de la excesiva isquemia que siempre precede a la menstruación, y que exagera aún más la hiperestesia simpática. c) Espasmodización uterina de asiento fundamental en cuello, donde al parecer, se ha demostrado un entrecruzamiento de fibras nerviosas autónomas.

d) Desequilibrio expulsivo a consecuencia de la congestión uterina menstrual y el cierre espasmódico del cuello, lo que ocasiona contracciones dolorosas para vencer el espasmo, siendo tanto más dolorosas cuanto mayor sea su amplitud.

e) Colaboración de sustancias occitócicas de la sangre, para intensificar los dolores ("menotoxina" de Smith, o "estimulantes menstruales" de Picles y Clitheroe).

B) Anoxia uterina. Si la isquemia del endometrio es fisiológicamente necesaria para que pueda verificarse la menstruación, es lógico pensar que si esta isquemia se exagera aparezcan trastornos, y que estos trastornos, a semejanza de lo que sucede en tantos otros órganos de la economía -corazón, músculos de las extremidades-, se manifiesten en forma dolorosa. Es el denominado "angor pélvico" por muchos autores.

Lo que sí se discute, a semejanza del aparato anterior, es la naturaleza de esta anoxia. Mientras que para unos se trataría de una insuficiencia de riego arterial por vasoespasmo natural exagerado, mecánico (contracciones exageradas con aumento de la presión intrauterina) o debido a sustancias vasoconstrictoras (adrenérgicas 0 serotonina), para otros sería una anoxia por congestión venosa provocada por cambios metabólicos, vegetativos o psicosomáticos, y finalmente, hay quienes sostienen que se trataría de una combinación de ambos factores -arterial y venoso- o de una constelación patogénica en la que interviene 
el elemento vascular como uno más de primordial importancia.

\section{C) Disregulación psicosomática.} Mientras no se llegó a demostrar la cada vez superior importancia de los hallazgos anatómicos en las pacientes dismenorreicas y las investigaciones estadísticas fueron descartando muchos de los pretendidos factores responsables del dolor, la creencia de que se trata de una afección más de la esfera psíquica que de la somática, estaba muy extendida.

Posteriormente se fueron imbricando sobre esta teoría una serie de hechos -liberación de hormonas con propiedades occitócicas y vasopresoras, disregulación del equilibrio progesterona-estrógenos, retención de sodio y agua por hipercorticalismo secundario a una estimulación hipofisaria anormal, etc.- que ha obligado a unos cuantos investigadores a pronunciarse en favor de una disregulación compleja, en la cual la misma hipoplasia uterina, tan invocada como responsable de la dismenorrea, no sería más que otro acompañante del cortejo de inmadurez psicosomática.

Basándonos en estos hechos y sabiendo las dificultades del tratamiento de este complejo síndrome, empleamos un antiespasmódico - anal- gésico (Bromuro de N - Butil - Hioscina + Aminofenazona)* y un vasodilatador periférico (Oxifenil - Oxibutilaminoetano)**.

\section{II - Farmacología}

El Bromuro de N-Butil-Hioscina tiene su punto de acción en los ganglios parasimpáticos de la musculatura lisa, inhibiendo los estímulos. De este punto de acción específico resultan las ventajas del medicamento en comparación a otros fármacos, especialmente los derivados de la atropina que disminuyen el tono del parasimpático en todo el organismo. Gracias a esta acción se eliminaron prácticamente los efectos secundarios conocidos: Acomodación ocular, midriasis, sequedad de boca y taquicardia.

Esta droga está asociada al fenildimetil - pirazolón - metilaminometan sulfonato sódico, conocido por su acción analgésica central, así como también con efecto antiflogístico y antipirético. Además provoca una disminución de la irritabilidad de las fibras musculares, lo que equivale a un ligero efecto espasmolítico.

* Buscapina Compositum - C. H. Boehringer Sohn - Ingelheim am Rhein.

** Vasculat - C. H. Boehringer Sohn - Ingelheim am Rhein - Alemania.

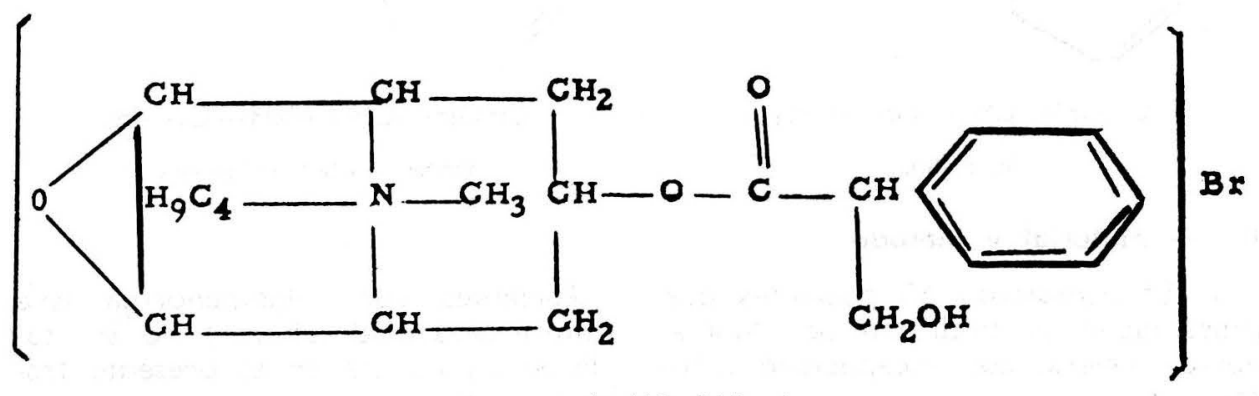

Bromuro de N-Butil-Hioscina 


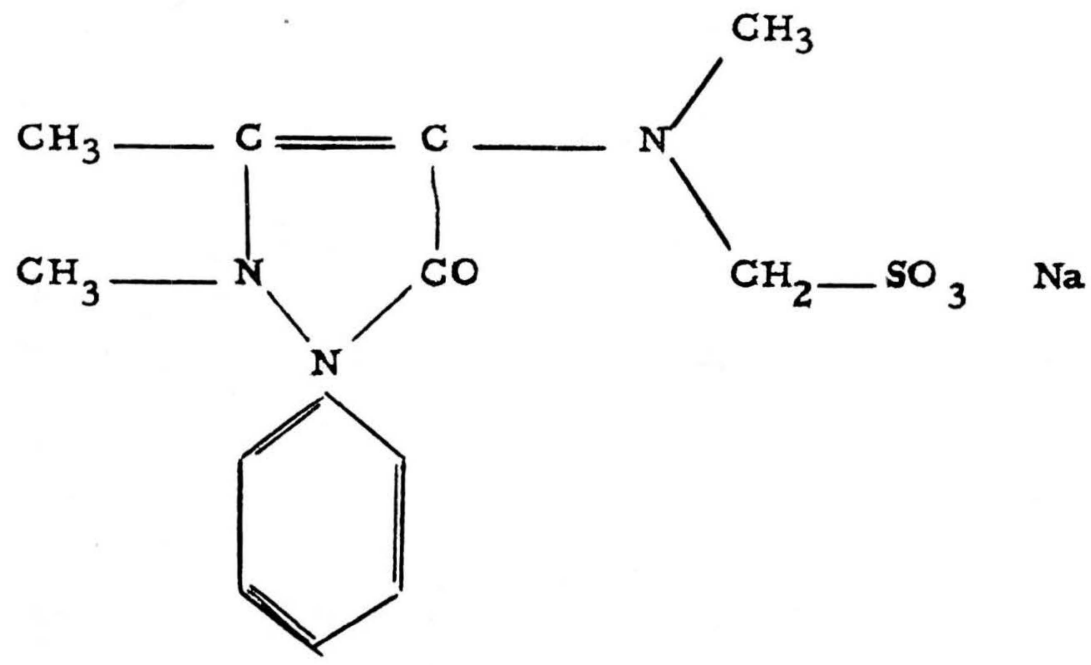

Fenil-dimetil-pirazolón-metilaminometan-sulfonato sódico

El Oxifenil-Oxibutilaminoetano es un compuesto derivado de la adrenalina obtenido por reemplazo del grupo metílico del átomo de nitrógeno de la cadena lateral por un radical butílico que le confiere la propiedad vasodilatadora, por estimula-

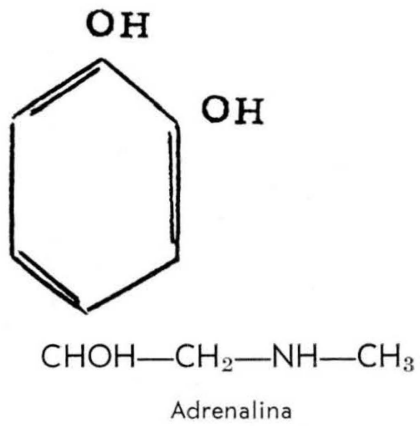

\section{III - Material y Método}

1. Se estudiaron 60 pacientes que presentaban el síndrome de algomenorrea severa, con incapacidad laboral. ción preponderante de los receptores beta. Al mismo tiempo se conserva el efecto inotropo lográndose con este doble mecanismo no solamente una vasodilatación periférica, sino también un mayor flujo sanguíneo.

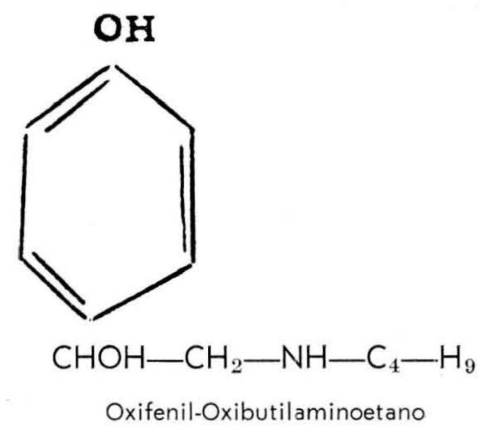

Pacientes con algomenorrea leve ( $\sin$ incapacidad laboral) no se tuvieron en cuenta en el presente trabajo. 


\begin{tabular}{lcr}
\hline $\begin{array}{l}\text { Clasificación } \\
\text { Algomenorreas }\end{array}$ & $\begin{array}{c}\text { No. de } \\
\text { pacientes }\end{array}$ & $\%$ \\
\hline $\begin{array}{l}\text { Primaria tipo } \\
\text { espasmódico }\end{array}$ & 25 & 41.67 \\
$\begin{array}{l}\text { Secundaria tipo } \\
\text { espasmódico }\end{array}$ & 35 & 58.33 \\
TOTAL & 60 & 100.00 \\
\hline
\end{tabular}

$2{ }^{\circ}$ A cada paciente se le administró un tratamiento combinado consistente en cuatro tabletas diarias de Buscapina Compositum y 20 gotas de Vasculat cada ocho horas.

3․ Este tratamiento se administró durante la menstruación y generalmente en dos o tres ciclos sucesivos.

4. Desde el punto de vista clínico no se encontraron anomalías de significación, como causas orgánicas aparentes del padecimiento.

5: A la gran mayoría de pacientes se practicó estudios de la función ovárica, es decir: citología vaginal y cristalización del moco cervical durante un ciclo menstrual, con intervalo de cinco días, y biopsia de endometrio practicada el primero o segundo día del ciclo.

6: A algunas pacientes no fue posible hacer estos exámenes, generalmente por asuntos de orden técnico, o en ocasiones por negligencia de la paciente.

7: La edad de las pacientes estudiadas osciló entre los 17 y los 43 años, siendo más frecuentes las comprendidas entre los 20 y 30 años.

\section{IV - Resumen y Conclusiones}

Considerando que la algomenorrea severa es un síntoma bastante frecuente en la mujer y que es causa común de incapacidad laboral, se han intentado numerosos tratamientos con el fin de aliviar los síntomas, habiéndose obtenido diversos resultados. En este trabajo se han seleccio- nado 60 casos de algomenorrea severa, los cuales han sido tratados mediante una asociación medicamentosa compuesta por Bromuro de N-ButilHioscina (anticolinérgico de síntesis I) y Oxifenil-Oxibutilaminoetano (vasodilatador adrenérgico); la primera, agente antiespasmódico de la musculatura lisa y analgésico, y la segunda, vasodilatador periférico y estimulante beta-adrenérgico. Se emplearon dosis corrientes de ambos medicamentos, 4 grageas diarias de Bromuro de N-Butil Hioscina, y 20 gotas cada ocho horas de OxifenilOxibutilaminoetano, administrados durante los días de la menstruación en dos o tres ciclos sucesivos.

\section{$\vee$ - Resultados}

Buenos

Regulares

Nulos

\begin{tabular}{rr}
45 & $75.18 \%$ \\
4 & $6.66 \%$ \\
11 & $18.16 \%$ \\
\hline 60 & $100.00 \%$
\end{tabular}

Entendemos por bueno si se suprime el dolor, o se observa una notoria mejoría.

Regular si persiste el dolor pero menos intenso, haciéndose tolerable.

Nulo, si persiste el dolor sin modificación (incapacita).

Los buenos resultados hallados demuestran la bondad de los fármacos usados, a la vez que su acción nos confirma el diagnóstico etiológico de dismenorrea psicógena. Se estudió en este trabajo un alto porcentaje $(40 \%)$ de factor endocrino por medio de biopsia de endometrio, citología y moco cervical, hallándose normalidad de función hipofiso-ovárica.

Es de esperar que con la enseñanza médica a la colectividad sobre los problemas psicogenitales, este síntoma irá desapareciendo lentamente en un futuro, ojalá no muy lejano. 


\begin{tabular}{|c|c|c|c|c|c|c|}
\hline Caso No & $\begin{array}{l}\text { Historia } \\
\text { Clin. } \mathbf{N}^{0}\end{array}$ & Edad & $\begin{array}{l}\text { Antecedentes de la } \\
\text { enfermedad actual }\end{array}$ & Examen Ginecológico & $\begin{array}{l}\text { Evolución posterior } \\
\text { al tratamiento }\end{array}$ & Resultados \\
\hline 1 & 267820 & 34 & $\begin{array}{l}\text { Menarquia: } 14 \text { años. Ciclos: } 30 \\
x \text { 5. Algomenorrea primaria de } \\
\text { mediana intensidad, tipo expul- } \\
\text { sivo, especialmente el primer } \\
\text { día del ciclo. Mastalgia pre- } \\
\text { menstrual de mediana intensi- } \\
\text { dad. }\end{array}$ & Negativo & $\begin{array}{l}\text { Disminuyó notoriamente el do- } \\
\text { ior, mejorando la continuidad } \\
\text { del flujo menstrual. }\end{array}$ & Bueno \\
\hline 2 & 204590 & 38 & $\begin{array}{l}\text { Menarquia: } 14 \text { años. Ciclos: } 30 \\
x \quad 4 \text {. Algomenorrea primaria ti- } \\
\text { po expulsivo intensa los tres } \\
\text { primeros dias de la menstrua- } \\
\text { ción. }\end{array}$ & Negativo & $\begin{array}{l}\text { Ausencia completa del dolor en } \\
\text { las menstruaciones sucesivas. }\end{array}$ & Bueno \\
\hline 3 & 612905 & 22 & $\begin{array}{l}\text { Menarquia: } 13 \text { años. Ciclos: } 30 \\
x \text { 6. Algomenorrea primaria ti- } \\
\text { po expulsivo, intensa los dos } \\
\text { primeros días de la menstrua- } \\
\text { ción. }\end{array}$ & Negativo & $\begin{array}{l}\text { En el primer ciclo se obser:ó } \\
\text { alivio notorio del dolor, persis- } \\
\text { tiendo éste en grado discreto. } \\
\text { En el segundo ciclo la mens- } \\
\text { truación fué indolora. }\end{array}$ & Bueno \\
\hline 4 & 540920 & 33 & $\begin{array}{l}\text { Menarquia: } 13 \text { años. Ciclos: } \\
120-150 \times 4 \text {. Después del trata- } \\
\text { miento hormonal presenta ciclos } \\
\text { de } 28-30 \times 3 \text {. Algomenorrea se- } \\
\text { cundaria, tipo expulsiva, con } \\
\text { dolor intenso en el bajo vien- } \\
\text { tre los dos primeros días de la } \\
\text { menstruación. }\end{array}$ & Negativo & $\begin{array}{l}\text { Ausencia del dolor en las reglas } \\
\text { posteriores, notándose especial } \\
\text { alivio con el Vasculat, al pare- } \\
\text { cer por aumento del flujo mens- } \\
\text { trual. }\end{array}$ & Bueno \\
\hline 5 & 456526 & 25 & $\begin{array}{l}\text { Menarquia: } 13 \text { años. Ciclos: } 30 \\
x \quad 3 \text {. Hipomenorrea. Algomeno- } \\
\text { rrea secundaria tipo expulsiva } \\
\text { intensa, durante los dos prime- } \\
\text { ros días de menstruación. }\end{array}$ & Negativo & $\begin{array}{l}\text { Mejoró ligeramente en relación } \\
\text { al dolor menstrual, ya que éste } \\
\text { persistió haciéndose más tolera- } \\
\text { ble. }\end{array}$ & Regular \\
\hline 6 & 55665 & 35 & $\begin{array}{l}\text { Menarquia: } 13 \text { años. Ciclos: } 23 \\
x \text { 3. Algomenorrea primaria ti- } \\
\text { po expulsiva, intensa los dos } \\
\text { primeros días de la regla. }\end{array}$ & $\begin{array}{l}\text { Nódulos miomatosos en cuerpo } \\
\text { uterino. Citología: normal. Biop- } \\
\text { sia de endometrio: "Endometrio } \\
\text { menstrual". }\end{array}$ & $\begin{array}{l}\text { En la primera menstruación } \\
\text { disminuyó el dolor, persistiendo } \\
\text { durante el segundo ciclo. }\end{array}$ & Regular \\
\hline
\end{tabular}




\begin{tabular}{|c|c|c|c|c|c|c|}
\hline Caso $\mathrm{N}^{0}$ & $\begin{array}{l}\text { Historia } \\
\text { Clin. } \mathrm{N}^{0}\end{array}$ & Edad & $\begin{array}{l}\text { Antecedentes de la } \\
\text { enfermedad actual }\end{array}$ & Examen Ginecológico & $\begin{array}{l}\text { Evolución posterior } \\
\text { al tratamiento }\end{array}$ & Resultados \\
\hline 7 & 577244 & 29 & $\begin{array}{l}\text { Menarquia: } 14 \text { años. Ciclos: } 23 \\
x \text { 3. Algomenorrea primaria ti- } \\
\text { po expulsiva, intensa los dos } \\
\text { primeros días de la regla. }\end{array}$ & Cervicitis (tratada). & No se observó mejoría. & Nulo \\
\hline 8 & 451389 & 18 & $\begin{array}{l}\text { Menarquia: } 12 \text { años. Ciclos: } 25- \\
30 \times 3 \text {. Algomenorrea secunda- } \\
\text { ria de tres meses de evolución, } \\
\text { intensa tipo expulsivo. Mastalgia } \\
\text { menstrual. }\end{array}$ & Negativo & $\begin{array}{l}\text { Disminuyó el dolor ligeramente, } \\
\text { persistiendo en forma menos } \\
\text { acentuada. }\end{array}$ & Regular \\
\hline 9 & 582071 & 26 & $\begin{array}{l}\text { Menarquia: } 14 \text { años. Ciclos: } 30 \\
x \quad 4 \text {. Algomenorrea secundaria } \\
\text { de cinco años de evolución, ti- } \\
\text { po expulsivo, el primer día de } \\
\text { la menstruación. }\end{array}$ & Negativo & $\begin{array}{l}\text { Menstruación completamente in- } \\
\text { dolora. }\end{array}$ & Bueno \\
\hline 10 & 314257 & 23 & $\begin{array}{l}\text { Menarquia: } 13 \text { años. Ciclos: } 28 \\
29 \times 5 . \text { Algomenorrea secunda- } \\
\text { ria tipo expulsivo, sensación de } \\
\text { inflamación abdominal, vómito, } \\
\text { sudoración y neurastenia. }\end{array}$ & Negativo & $\begin{array}{l}\text { Se observó mejoría notoria de } \\
\text { los síntomas dolorosos. }\end{array}$ & Bueno \\
\hline 11 & 496526 & 26 & $\begin{array}{l}\text { Menarquia: } 13 \text { años. Ciclos: } 30 \\
x \text { 3. Algomenorrea primaria in- } \\
\text { tensa tipo expulsivo, cefálea, } \\
\text { náuseas. Estos síntomas se pre- } \\
\text { sentan durante todo el tiempo } \\
\text { de la menstruación. }\end{array}$ & Negativo & $\begin{array}{l}\text { Disminuyeron los síntomas dolo- } \\
\text { rosos, persistiendo el estado } \\
\text { nauseoso. }\end{array}$ & Bueno \\
\hline 12 & 449319 & 30 & $\begin{array}{l}\text { Menarquia: } 16 \text { años. Ciclos: } 30 \\
\text { x 3. Algomenorrea primaria tipo } \\
\text { expulsivo, inflamación abdomi- } \\
\text { nal, de regular intensidad du- } \\
\text { rante los dos primeros días de } \\
\text { la menstruación. }\end{array}$ & Negativo & Suspensión completa del dolor. & Bueno \\
\hline
\end{tabular}




\begin{tabular}{|c|c|c|c|c|c|c|c|}
\hline Caso $N^{0}$ & $\begin{array}{l}\text { Historia } \\
\text { Clin. } \mathrm{N}^{\mathrm{o}}\end{array}$ & Edad & $\begin{array}{l}\text { Antecedentes de la } \\
\text { enfermedad actual }\end{array}$ & Examer & en Ginecológico & $\begin{array}{l}\text { Evolución posterior } \\
\text { al tratamiento }\end{array}$ & Resultados \\
\hline 13 & 579389 & 32 & $\begin{array}{l}\text { Menarquia: } 14 \text { años. Ciclos: } 28 \\
x \quad 4-5 \text {. Algomenorrea primaria } \\
\text { severa, tipo expulsivo, la cual } \\
\text { se ha presentado desde la me- } \\
\text { narquia. }\end{array}$ & & Negativo & No hubo ninguna mejoría. & Nulo \\
\hline 14 & 144291 & 32 & $\begin{array}{l}\text { Menarquia: } 15 \text { años. Ciclo: } 30 \\
x \text { 2-3. Algomenorrea secundaria } \\
\text { a intervención quirúrgica (mio- } \\
\text { mectomía, ooforectomía), tipo } \\
\text { expulsivo acompañada de náu- } \\
\text { seas y lipotimias. Estos sínto- } \\
\text { mas se presentan el primer día } \\
\text { de la menstruación. }\end{array}$ & $\begin{array}{l}\text { Cuello con } \\
\text { cial. }\end{array}$ & ectropión periorifi- & $\begin{array}{l}\text { Hubo mejoría de los síntomas } \\
\text { dolorosos. }\end{array}$ & Bueno \\
\hline 15 & 215709 & 28 & $\begin{array}{l}\text { Menarquia: } 13 \text { años. Ciclos: } 30 \\
x \text { 6-8. Algomenorrea primaria } \\
\text { los tres primeros días del ciclo. } \\
\text { Dolor en el bajo vientre, tipo } \\
\text { expulsivo. }\end{array}$ & & Negativo & $\begin{array}{l}\text { No hubo ninguna mejoría res- } \\
\text { pecto al dolor. }\end{array}$ & Nulo \\
\hline 16 & 592536 & 26 & $\begin{array}{l}\text { Menarquia: } 13 \text { años. Ciclos: } 28 \\
30 \times 4-5 \text {. Algomenorrea prima- } \\
\text { ria intensa, total, tipo expulsi- }\end{array}$ & $\begin{array}{l}\text { Cuerpo uterir } \\
\text { na relación } \\
\text { vo. }\end{array}$ & $\begin{array}{l}\text { ino pequeño con bue- } \\
\text { cérvico corporal. }\end{array}$ & $\begin{array}{l}\text { Se observó notoria mejoría del } \\
\text { dolor. }\end{array}$ & Bueno \\
\hline 17 & 254043 & 33 & $\begin{array}{l}\text { Menarquia: } 14 \text { años. Ciclos: } 22 \\
24 \times 4 \text {. Algomenorrea primaria } \\
\text { intensa tipo expulsiva, escalofrío } \\
\text { el primer día de la menstrua- } \\
\text { ción. }\end{array}$ & Cuello con e & ectropión. & $\begin{array}{l}\text { Se suprimió completamente el } \\
\text { dolor. }\end{array}$ & Bueno \\
\hline 18 & 630780 & 29 & $\begin{array}{l}\text { Menarquia: } 14 \text { años. Ciclos: } 30 \\
x \quad 3-4 \text {. Algomenorrea primaria } \\
\text { intensa los dos primeros días } \\
\text { de la regla e nforma de dolo- } \\
\text { res en las fosas iliacas tipo in- } \\
\text { flamatorio. }\end{array}$ & & Negativo & $\begin{array}{l}\text { Hubo completa mejoría en los } \\
\text { ciclos siguientes. }\end{array}$ & Bueno \\
\hline
\end{tabular}




\begin{tabular}{|c|c|c|c|c|c|c|}
\hline Caso $\mathrm{N}^{\mathrm{o}}$ & $\begin{array}{l}\text { Historia } \\
\text { Clin. } \mathrm{N}^{0}\end{array}$ & Edad & $\begin{array}{l}\text { Antecedentes de la } \\
\text { enfermedad actual }\end{array}$ & Examen Ginecológico & $\begin{array}{l}\text { Evolución posterior } \\
\text { al tratamiento }\end{array}$ & Resultados \\
\hline 19 & 601498 & 25 & $\begin{array}{l}\text { Menarquia: } 12 \text { años. Ciclos: } 20 \\
25 \times 4 \text {. Algomenorrea secunda- } \\
\text { ria de cinco años de evolución } \\
\text { consistente en dolor hipogástaico } \\
\text { tipo expulsivo los dos primeros } \\
\text { días de la regla. }\end{array}$ & $\begin{array}{l}\text { Cuerpo en retroversión } 2^{\circ} \text { con } \\
\text { diámetro disminuído. }\end{array}$ & $\begin{array}{l}\text { Se observó disminución notoria } \\
\text { del dolor. }\end{array}$ & Bueno \\
\hline 20 & 424406 & 21 & $\begin{array}{l}\text { Menarquia: } 14 \text { años. Ciclos: } 30 \\
x \text { 2-3. Algomenorrea secundaria } \\
\text { de tres meses de evolución, con- } \\
\text { sistente en dolor abdominal ge- } \\
\text { neralizado durante todos los días } \\
\text { de la regla. Tipo expulsivo. }\end{array}$ & Negativo & $\begin{array}{l}\text { Hubo mejoría aunque persiste } \\
\text { el dolor en grado moderado. }\end{array}$ & Bueno \\
\hline 21 & 279916 & 23 & $\begin{array}{l}\text { Menarquia: } 13 \text { años. Ciclos: } 30 \\
x \text { 8. Algomenorrea secundaria } \\
\text { de un año de evolución. Dolor } \\
\text { hipogástrico tipo expulsivo el } \\
\text { primer día de la regla, acompa- } \\
\text { ñado de náuseas, escalofrío y } \\
\text { cefáleas. }\end{array}$ & Cuerpo uterino en RV grado III. & No se observó mejoría & Nulo \\
\hline 22 & 627738 & 20 & $\begin{array}{l}\text { Menarquia: } 12 \text { años. Ciclos: } 28 \\
x \text { 5. Algomenorrea primaria de } \\
\text { dolor intenso, tipo expulsivo, el } \\
\text { primer día de la regla. Mastal- } \\
\text { gia pre-menstrual. }\end{array}$ & Negativo & $\begin{array}{l}\text { Se observó disminución del do- } \\
\text { lor. }\end{array}$ & Bueno \\
\hline 23 & 445217 & 20 & $\begin{array}{l}\text { Menarquia: } 14 \text { años. Ciclos: } 30 \\
x \quad 3 \text {. Algomenorrea secundaria, } \\
\text { dolor intenso en fosas ilíacas, } \\
\text { tipo expulsivo, durante todo el } \\
\text { tiempo de la menstruación. }\end{array}$ & $\begin{array}{l}\text { Del } 5 \text { al } 28{ }^{\circ} \text { día se hicieron } \\
\text { exámenes citológicos siendo } \\
\text { compatibles con el día del ciclo } \\
\text { registrado. El día } 21,40 \% \text { de } \\
\text { picnosis y maduración. El día } \\
25 \text { picnosis y maduración } 65 \% \text {, } \\
\text { siendo un porcentaje alto. }\end{array}$ & Se suspendió el dolor. & Bueno \\
\hline 24 & 582591 & 20 & $\begin{array}{l}\text { Menarquia: } 12 \text { años. Ciclos: } 30 \\
x \quad 4 \text {. Algomenorrea primaria } \\
\text { desde el día anterior, dolor en } \\
\text { fosas ilíacas, tipo expulsivo, dia- } \\
\text { rrea, lividez, lipotimias. }\end{array}$ & Negativo & $\begin{array}{l}\text { Tuvo dolor en la fosa ilíaca de- } \\
\text { recha menos intenso. Desapari- } \\
\text { ción de la diarrea y el vómito. } \\
\text { Se hizo citología. }\end{array}$ & Bueno \\
\hline
\end{tabular}




\begin{tabular}{|c|c|c|c|c|c|c|}
\hline Caso $\mathrm{N}^{0}$ & $\begin{array}{l}\text { Historia } \\
\text { Clin. } \mathrm{N}^{0}\end{array}$ & Edad & $\begin{array}{l}\text { Antecedentes de la } \\
\text { enfermedad actual }\end{array}$ & Examen Ginecológico & $\begin{array}{l}\text { Evolución posterior } \\
\text { al tratamiento }\end{array}$ & Resultados \\
\hline 25 & 272788 & 24 & $\begin{array}{l}\text { Menarquia: } 14 \text { años. Ciclos: } 30 \\
\text { x } 8 \text {. Algomenorrea secundaria } \\
\text { hace } 4 \text { años, acompañada de có- } \\
\text { lico hipogástrico intenso, tipo } \\
\text { expulsivo, diarrea y vómito los } \\
\text { dos primeros días. }\end{array}$ & $\begin{array}{l}\text { Retroversión uterina fija, dolo- } \\
\text { rosa. }\end{array}$ & No hubo ninguna mejoría. & Nulo \\
\hline 26 & 282858 & 30 & $\begin{array}{l}\text { Menarquia: } 13 \text { años. Ciclos: } 30 \\
x \text { 15-10. Algomenorrea secunda- } \\
\text { ria de cinco años de evolución } \\
\text { ( } 19 \text { y } 2^{\circ} \text { día del ciclo), inten- } \\
\text { sa tipo expulsiva, acompañada } \\
\text { de dolor sacro lumbar. }\end{array}$ & $\begin{array}{l}\text { Nódulos miomatosos en cara an- } \\
\text { terior del útero. Citología vagi- } \\
\text { nal: Estímulo estrogénico ade- } \\
\text { cuado. Moco cervical: Normal. } \\
\text { Biopsia de endometrio: Tejido } \\
\text { insuficiente. }\end{array}$ & $\begin{array}{l}\text { Se alivió completamente. Dice } \\
\text { haber sentido especial alivio al } \\
\text { tomar el Vasculat. Se hizo cito- } \\
\text { logía. }\end{array}$ & Bueno \\
\hline 27 & 358236 & 37 & $\begin{array}{l}\text { Menarquia: } 16 \text { años. Ciclos: } 60 \\
45 \times 3-4 \text {. Algomenorrea secun- } \\
\text { daria de tres años de evolu- } \\
\text { ción, dolor intenso tipo expul- } \\
\text { sivo, calofrío (la víspera y el } \\
\text { primer día de la regla). Oligo- } \\
\text { menorrea: Tratada con ciclos } \\
\text { artificiales (progesterona y es- } \\
\text { tradiol) sin que con esto se } \\
\text { sintiera mejoría en el dolor. }\end{array}$ & Cuello ectropión. & $\begin{array}{l}\text { Supresión total del dolor y las } \\
\text { molestias. }\end{array}$ & Bueno \\
\hline 28 & 602899 & 29 & $\begin{array}{l}\text { Menarquia: } 10 \text { años. Ciclos: } 28 \\
30 \times 3 \text {. Algomenorrea primaria. } \\
\text { Acompañada desde el principio } \\
\text { de dolor hipogástrico tipo ex- } \\
\text { pulsivo, en fosas ilíacas (inten- } \\
\text { so el primer día). Expulsión de } \\
\text { coágulos. }\end{array}$ & Negativo & Ligero alivio del dolor. & Regular \\
\hline 29 & 66669 & 39 & $\begin{array}{l}\text { Menarquia: } 12 \text { años. Ciclos: } 30 \\
x \text { 4-5. Algomenorrea secundaria } \\
\text { de dos años de evolución, tipo } \\
\text { expulsiva, cuatro días antes y } \\
\text { los dos primeros del ciclo. }\end{array}$ & $\begin{array}{l}\text { Cistouretrocele } 1^{9} \text { Citología vagi- } \\
\text { nal: Normal. M. Cervical: Nor- } \\
\text { mal. Biopsia de endometrio: } \\
\text { "Endometrio pregravídico co.l } \\
\text { avanzados cambios menstrua- } \\
\text { les". }\end{array}$ & $\begin{array}{l}\text { No se notó mejoría en el pri- } \\
\text { mer ciclo. En los restantes hu- } \\
\text { bo notoria mejoría del dolor. }\end{array}$ & Bueno \\
\hline
\end{tabular}




\begin{tabular}{|c|c|c|c|c|c|c|}
\hline Caso $\mathrm{N}^{0}$ & $\begin{array}{l}\text { Historia } \\
\text { Clin. } \mathbf{N}^{\mathbf{9}}\end{array}$ & Edad & $\begin{array}{l}\text { Antecedentes de la } \\
\text { enfermedad actual }\end{array}$ & Examen Ginecológico & $\begin{array}{l}\text { Evolución posterior } \\
\text { al tratamiento }\end{array}$ & Resultados \\
\hline 30 & 422192 & 23 & $\begin{array}{l}\text { Menarquia: } 13 \text { años, Ciclos: } 30 \\
\text { x 3-4. Después del último parto, } \\
\text { un año ciclos de } 40 \text { a } 60 \times 8 \\
\text { a } 10 \text {. Algomenorrea secundaria } \\
\text { de cuatro meses de evolución, } \\
\text { tipo expulsiva, dolor intenso en } \\
\text { abdomen inferior, calores en la } \\
\text { cara los tres primeros días. } \\
\text { Mastalgia pre-menstrual. }\end{array}$ & Negativo & $\begin{array}{l}\text { Ausencia total del dolor durar:- } \\
\text { te los dias de la menstruación. }\end{array}$ & Bueno \\
\hline 31 & 681967 & 18 & $\begin{array}{l}\text { Algomenorrea secundaria severa } \\
\text { total, tipo expulsivo. Menarquia: } \\
12 \text { años. Ciclos: } 18-20 \times 4-8 \text {. }\end{array}$ & $\begin{array}{l}\text { Negativo. Citología vaginal fun- } \\
\text { ción ovárica: Normal. Cristaliza- } \\
\text { ción moco cervical: Normal. } \\
\text { Biopsia de endometrio: Endo- } \\
\text { metrio secretor con cambios } \\
\text { menstruales. }\end{array}$ & Bastante alivio del dolor. & Bueno \\
\hline 32 & 483705 & 21 & $\begin{array}{l}\text { Algomenorrea secundaria post- } \\
\text { matrimonial ( } 21 / 2 \text { años), inten- } \\
\text { sa tipo expulsiva. Intervención } \\
\text { hace un año (ooforectomía uni- } \\
\text { lateral por quiste ovárico). }\end{array}$ & $\begin{array}{l}\text { Citología vaginal: función ová- } \\
\text { rica: Normal. Cristalización del } \\
\text { moco cervical: normal. Biopsia } \\
\text { de endometrio: restos decidua- } \\
\text { les inflamados. Endometrio en } \\
\text { estado secretorio. }\end{array}$ & Hubo mejoría. & Bueno \\
\hline 33 & 626401 & 25 & $\begin{array}{l}\text { Algomenorrea primaria primero y } \\
\text { segundo día de la menstruación. } \\
\text { Tipo expulsivo, náuseas. Menar- } \\
\text { quia: } 12 \text { años. Ciclos: } 30-26 \\
\text { x } 3 .\end{array}$ & Negativo & $\begin{array}{l}\text { Mejoró notoriamente. Pudo con- } \\
\text { currir al trabajo durante los ci- } \\
\text { clos sucesivos. }\end{array}$ & Bueno \\
\hline 34 & 639296 & 21 & $\begin{array}{l}\text { Algomenorrea primaria progre } \\
\text { siva primero y segundo día. } \\
\text { Menstruación tipo expulsiva, se- } \\
\text { vera, vómito lipotimia. Menar- } \\
\text { quia: } 14 \text { años. Ciclos: } 28-29 \\
\text { x } 3 .\end{array}$ & $\begin{array}{l}\text { Citología vaginal: función ová- } \\
\text { rica: normal. Buena actividad } \\
\text { estrogénica. Moco cervical: nor- } \\
\text { mal. Biopsia de endometrio: } \\
\text { técnicamente no se pudo hacer. }\end{array}$ & No se observó mejoría. & Nulo \\
\hline
\end{tabular}




\begin{tabular}{|c|c|c|c|c|c|c|}
\hline Caso $\mathrm{N}^{0}$ & $\begin{array}{l}\text { Historia } \\
\text { Clin. } \mathbf{N}^{0}\end{array}$ & Edad & $\begin{array}{l}\text { Antecedentes de la } \\
\text { enfermedad actual }\end{array}$ & Examen Ginecológico & $\begin{array}{l}\text { Evolución posterior } \\
\text { al tratamiento }\end{array}$ & Resultados \\
\hline 35 & 520503 & 23 & $\begin{array}{l}\text { Menarquia: } 15 \text { años. Ciclos: } 30 \\
x \quad 2-3 \text {. Algomenorrea secundaria } \\
\text { intensa, tipo expulsivo, el pri- } \\
\text { mer día. }\end{array}$ & $\begin{array}{l}\text { Hipoplasia uterina I grado. Cito- } \\
\text { logía vaginal, función ovárica: } \\
\text { normal. Moco cervical: normal. } \\
\text { Biopsia de endometrio: endo- } \\
\text { metrio progravídico con cam- } \\
\text { bios menstruales. }\end{array}$ & $\begin{array}{l}\text { Notoria mejoría con el trata- } \\
\text { miento. }\end{array}$ & Bueno \\
\hline 36 & 563278 & 23 & $\begin{array}{l}\text { Algomenorrea secundaria de } 4 \\
\text { años de evolución, severa, tipo } \\
\text { expulsivo primero y segundo dia. } \\
\text { Náuseas. Mastalgia pre-mens- } \\
\text { trual. }\end{array}$ & $\begin{array}{l}\text { Negativo. Citología vaginal: nor- } \\
\text { mal. }\end{array}$ & No se observó mejoría. & Nulo \\
\hline 37 & 647250 & 21 & $\begin{array}{l}\text { Menarquia: } 14 \text { años. Ciclos: } 28 \\
\times 4 \text {. Algomenorrea primaria se- } \\
\text { vera, tipo expulsiva, rebelde a } \\
\text { analgésicos. Causa incapacidad. }\end{array}$ & $\begin{array}{l}\text { Negativo. Citología vaginal, fun- } \\
\text { ción ovárica normal. }\end{array}$ & $\begin{array}{l}\text { Alivio marcado de los síntomas } \\
\text { dolorosos. }\end{array}$ & Bueno \\
\hline 38 & 421545 & 29 & $\begin{array}{l}\text { Menarquia: } 13 \text { años. Ciclos: } 30 \\
\times 3 \text {. Algomenorrea secundaria } \\
\text { total de tres meses de evolu- } \\
\text { ción. Tipo expulsiva. Hipomeno- } \\
\text { rrea. }\end{array}$ & $\begin{array}{l}\text { Negativo. Citología vaginal: hi- } \\
\text { poestrogenismo. Moco cervical: } \\
\text { no cristalización. Biopsia de en- } \\
\text { dometrio: Endometrio secretor } \\
\text { con cambios menstruales. }\end{array}$ & Completa mejoría del dolor. & Bueno \\
\hline 39 & 422192 & 23 & $\begin{array}{l}\text { Menarquia: } 13 \text { años. Ciclos: } 30 \\
60 \times 3-6 \text {. Algomenorrea secun- } \\
\text { ciaria de dos años de evolu- } \\
\text { ción, intenso dolor hipogástri- } \\
\text { co por dos días a partir del } \\
\text { primer día de la menstruación } \\
\text { tipo expulsivo. }\end{array}$ & $\begin{array}{l}\text { Normal. Citología vaginal: nor- } \\
\text { mal. Moco cervical: normal. }\end{array}$ & Alivio del dolor. & Bueno \\
\hline 40 & 681976 & 21 & $\begin{array}{l}\text { Menarquia: } 13 \text { años. Ciclos: } 30 \\
40 \times 3 \text {. Algomenorrea secunda- } \\
\text { ria de dos años de evolución. } \\
\text { Dolor lumbosacro los dos prime- } \\
\text { ros días de la menstruación, ti. } \\
\text { po expulsivo. }\end{array}$ & $\begin{array}{l}\text { Negativo. Citoiogía vaginal: nor- } \\
\text { mal. Moco cervical: normal. } \\
\text { Biopsia de endometrio: endome- } \\
\text { trio menstrual (secretor). }\end{array}$ & Pasó completamente el dolor. & Bueno \\
\hline
\end{tabular}




\begin{tabular}{|c|c|c|c|c|c|c|}
\hline Caso $\mathrm{N}^{\mathrm{o}}$ & $\begin{array}{l}\text { Historia } \\
\text { Clin. } \mathbf{N}^{9}\end{array}$ & Edad & $\begin{array}{l}\text { enfermedad actual } \\
\text { Antecedentes de la }\end{array}$ & Examen Ginecológico & $\begin{array}{l}\text { Evolución posterior } \\
\text { al tratamiento }\end{array}$ & Resultados \\
\hline 41 & 637980 & 22 & $\begin{array}{l}\text { Menarquia: } 12 \text { años. Ciclos: } 30 \\
60-90 \times 6-9 \text {. Algomenorrea pri- } \\
\text { maria total, tipo expulsivo, do- } \\
\text { lor hipogástrico intenso, irradia- } \\
\text { do a muslos. }\end{array}$ & $\begin{array}{l}\text { Negativo. Citología vaginal: hi- } \\
\text { poestrogenismo. }\end{array}$ & Tuvo mejoría del dolor. & Bueno \\
\hline 42 & 662762 & 17 & $\begin{array}{l}\text { Menarquia: } 15 \text { años. Ciclos: } 28 \\
x \quad 4-5 \text {. Dismenorrea secundaria } \\
\text { de cinco meses de evolución, } \\
\text { tipo expulsiva severa. }\end{array}$ & Negativo & Pasó el dolor completamente. & Bueno \\
\hline 43 & 718767 & 41 & $\begin{array}{l}\text { Menarquia: } 14 \text { años. Ciclos: } 25 \\
30 \times 8-10 \text {. Algomenorrea secun- } \\
\text { daria de cinco años de evolu- } \\
\text { ción, dolor en fosas ilíacas, tipo } \\
\text { expulsivo. }\end{array}$ & $\begin{array}{l}\text { Negativo. Citología vaginal, fun- } \\
\text { ción ovárica: normal. Moco cer- } \\
\text { vical: normal. Biopsia de endo- } \\
\text { metrio: Endometrio menstrual. }\end{array}$ & $\begin{array}{l}\text { Con el tratamiento ha sentido } \\
\text { alivio notorio del dolor mens- } \\
\text { trual. }\end{array}$ & Bueno \\
\hline 44 & 582748 & 28 & $\begin{array}{l}\text { Menarquia: } 17 \text { años. Ciclos: } 20 \\
x \text { 3. Algomenorrea secundaria } \\
\text { de } 6 \text { años de evolución, des- } \\
\text { pués del cuarto parto, tipo ex- } \\
\text { pulsivo, cólicos en fosas ilíacas, } \\
\text { el primero y segundo días del } \\
\text { ciclo. }\end{array}$ & Negativo. Anexos negativos. & $\begin{array}{l}\text { Mejoró con el tratamiento, es- } \\
\text { pecia'mente el primer ciclo. }\end{array}$ & Bueno \\
\hline 45 & 584042 & 24 & $\begin{array}{l}\text { Algomenorrea primaria severa, } \\
\text { tipo expulsivo. Causa incapaci- } \\
\text { dad. }\end{array}$ & $\begin{array}{l}\text { Negativo. Citología vaginal: Acti- } \\
\text { viclad estrogénica baja. }\end{array}$ & No tuvo mejoría. & Nulo \\
\hline 46 & 638272 & 43 & $\begin{array}{l}\text { Algomenorrea secundaria severa } \\
\text { tipo expulsiva. }\end{array}$ & $\begin{array}{l}\text { Normal. Citología vaginal: acti- } \\
\text { vidad estrogénica baja. Moco } \\
\text { cervical: normal. Biopsia de en- } \\
\text { dometrio: Endometrio secretor. }\end{array}$ & Pasó el dolor completamente. & Bueno \\
\hline 47 & 582748 & 28 & $\begin{array}{l}\text { Menarquia: } 13 \text { años. Ciclos: } 30 \\
x \quad 3 \text {. Algomenorrea secundaria } \\
\text { severa de cinco años de evolu- } \\
\text { ción, tipo expulsiva. Los dos } \\
\text { primeros días localización en fo- } \\
\text { sas ilíacas. Incapacita. }\end{array}$ & $\begin{array}{l}\text { Retroflexión uterina II (no vino } \\
\text { a estudio de función ovárica. }\end{array}$ & Pasó el dolor completamente. & Bueno \\
\hline
\end{tabular}




\begin{tabular}{|c|c|c|c|c|c|c|}
\hline Caso $\mathrm{N}^{0}$ & $\begin{array}{l}\text { Historia } \\
\text { Clin. } \mathrm{N}^{9}\end{array}$ & Edad & $\begin{array}{l}\text { Antecedentes de la } \\
\text { enfermedad actual }\end{array}$ & Examen Ginecológico & $\begin{array}{l}\text { Evolución posterior } \\
\text { al tratamiento }\end{array}$ & Resultados \\
\hline 48 & 639896 & 21 & $\begin{array}{l}\text { M=narquia: } 14 \text { años. Ciclos: } 28 \\
x \text { 3. Algomenorrea primaria ti- } \\
\text { po expulsiva. }\end{array}$ & $\begin{array}{l}\text { Negativo. (No se hicieron exá- } \\
\text { menes de función ovárica). }\end{array}$ & No tuvo mejoría. & Nulo \\
\hline 49 & 491276 & 25 & $\begin{array}{l}\text { Menarquia: } 16 \text { años. Ciclos: } 40 \\
45 \times 8 \text {. Algomenorrea secundaria } \\
\text { severa primer día, tipo expulsi- } \\
\text { va. Incapacita. }\end{array}$ & $\begin{array}{l}\text { Negativo. Citclogía vaginal nor- } \\
\text { mal. Moco cervical normal. } \\
\text { Biopsia de endometrio: "Endo- } \\
\text { metrio pro-gravídico". }\end{array}$ & Pasó completamente el dolor. & Bueno \\
\hline 50 & 637971 & 26 & $\begin{array}{l}\text { Dismenorrea secundaria, seve- } \\
\text { ra tipo expulsiva, desde hace } \\
\text { dos años. }\end{array}$ & $\begin{array}{l}\text { Citología vaginal: actividad es- } \\
\text { trogénica baja. Biopsia de endo- } \\
\text { metrio. "Endometrio secretor } \\
\text { temprano". }\end{array}$ & Pasó completamente el dolor. & Buenc \\
\hline 51 & 407310 & 26 & $\begin{array}{l}\text { Algomenorrea primaria intensa, } \\
\text { tipo expulsiva. Mastalgia pre- } \\
\text { menstrual. Infertilidad. }\end{array}$ & $\begin{array}{l}\text { Negativo. Citología vaginal: li- } \\
\text { gero estímulo estrogénico. Biop- } \\
\text { sia de endometrio: No se prac- } \\
\text { ticó. }\end{array}$ & Pasó completamente el dolor. & Bueno \\
\hline 52 & 710473 & 25 & $\begin{array}{l}\text { Menarquia: } 16 \text { años. Ciclos: } 30 \\
\times 4 \text {. Algomenorrea primaria tipo } \\
\text { expuisiva, los dos primeros días. }\end{array}$ & $\begin{array}{l}\text { Negativo. Citología vaginal nor- } \\
\text { mal. Moco cervical: Normal. } \\
\text { Biopsia de endometrio: "Endo- } \\
\text { metrio menstrual" (secretor } \\
\text { avanzado). }\end{array}$ & Alivio completo del dolor. & Bueno \\
\hline 53 & 352264 & 30 & $\begin{array}{l}\text { Algomenorrea secundaria de } 10 \\
\text { años de evolución. Dolor abdo- } \\
\text { minal bajo, intenso, el primer } \\
\text { día del ciclo. Cefálea, lumbal- } \\
\text { gia. }\end{array}$ & $\begin{array}{l}\text { Negativo. No se hizo citología } \\
\text { ni biopsia de endometrio. }\end{array}$ & $\begin{array}{l}\text { No sintió mejoría con el trata- } \\
\text { miento. }\end{array}$ & Nulo \\
\hline 54 & 662762 & 18 & $\begin{array}{l}\text { Menarquia: } 15 \text { años. Ciclos: } 28 \\
x 4-5 \text {. Algomenorrea secundaria } \\
\text { de } 5 \text { meses de evolución, tipo } \\
\text { expulsivo, total, severa. }\end{array}$ & $\begin{array}{l}\text { Negativo. Citología vaginal: Mo- } \\
\text { derado estímulo estrogénico. } \\
\text { Moco cervical: } \\
\text { grado II. }\end{array}$ & $\begin{array}{l}\text { Pasó completamente el dolor } \\
\text { durante las menstruaciones. }\end{array}$ & Bueno \\
\hline 55 & 422192 & 24 & $\begin{array}{l}\text { Menarquia: } 13 \text { años. Ciclos: } 30 \\
x \quad 4 \text {. Algomenorrea secundaria } \\
\text { de } 6 \text { años de evolución, prime- } \\
\text { ro y segundo día. Tipo expul- } \\
\text { siva. }\end{array}$ & $\begin{array}{l}\text { Negativo. Citología vaginal nor- } \\
\text { mal. Biopsia de endometrio: } \\
\text { Endometrio típico del primer } \\
\text { día del ciclo. }\end{array}$ & Pasó completamente el dolor. & Bueno \\
\hline
\end{tabular}




\begin{tabular}{|c|c|c|c|c|c|c|}
\hline Caso $\mathrm{N}^{0}$ & $\begin{array}{l}\text { Historia } \\
\text { Clin. } \mathbf{N}^{0}\end{array}$ & Edad & $\begin{array}{l}\text { Antecedentes de la } \\
\text { enfermedad actual }\end{array}$ & Examen Ginecológico & $\begin{array}{l}\text { Evolución posterior } \\
\text { al tratamiento }\end{array}$ & Resultados \\
\hline 56 & 564376 & 30 & $\begin{array}{l}\text { Manarquia: } 14 \text { años. Ciclos: } 26 \\
28 \times 6 \text {. Algomenorrea primaria. } \\
\text { Primer día menstrual, intenso, } \\
\text { tipo expulsiva. }\end{array}$ & $\begin{array}{l}\text { Negativo. Citología vaginal: Mo- } \\
\text { derado estímulo estrogénico. } \\
\text { Moco cervical normal. Biopsia } \\
\text { de endometrio: "Endometrio } \\
\text { menstrual" (ler. día del ciclo). }\end{array}$ & Pasó completamente el dolor. & Bueno \\
\hline 57 & 615013 & 38 & $\begin{array}{l}\text { Algomenorrea secundaria de dos } \\
\text { meses de evolución, intensa, có- } \\
\text { lico hipogástrico y dolor lumbar } \\
\text { primero y segundo día mens- } \\
\text { trual. }\end{array}$ & $\begin{array}{l}\text { Retroversión uterina. Citología } \\
\text { vaginal: moderado estímulo es- } \\
\text { trogénico. Moco cervical: no } \\
\text { hubo cristalización. Biopsia de } \\
\text { endometrio: "Endometrio } \\
\text { menstrual". }\end{array}$ & Mejoró con el tratamiento. & Bueno \\
\hline 58 & 503933 & 30 & $\begin{array}{l}\text { Menarquia: } 14 \text { años. Ciclos: } 28 \\
x \text { 2. Algomenorrea primaria ti- } \\
\text { po expulsiva, severa, el primer } \\
\text { día de menstruación. }\end{array}$ & $\begin{array}{l}\text { Negativo. Citología vaginal: Es- } \\
\text { tímulo estrogénico normal. Ciclo } \\
\text { bifásico. Moco cervical: normal. } \\
\text { Biopsia de endometrio: endome- } \\
\text { trio secretor tardio. }\end{array}$ & Pasó el dolor completament:. & Bueno \\
\hline 59 & 411770 & 32 & $\begin{array}{l}\text { Menarquia: } 12 \text { años. Ciclos: } 25 \\
25 \times 6-8-10 \text {. Algomenorrea se- } \\
\text { cundaria severa de cinco me- } \\
\text { ses de evolución, tipo expulsiva, } \\
\text { los tres primeros días da mens- } \\
\text { truación. Posible origen psicóge- } \\
\text { no. }\end{array}$ & Negativo & Persistió la algomenorrea səvera. & Nulo \\
\hline 60 & 188861 & 27 & $\begin{array}{l}\text { Algomenorrea primaria, tipo ex- } \\
\text { pulsivo. }\end{array}$ & $\begin{array}{l}\text { Citología normal. Moco cervical } \\
\text { normal. Biopsia de endometrio: } \\
\text { Endometrio en fase pro-gravídi- } \\
\text { ca. }\end{array}$ & Mejoró completamenie. & Bueno \\
\hline
\end{tabular}




\section{VI - BIBLIOGRAFIA}

1 LASSEgue, C. J. Med. Paris 135, 295-313 1964.

2 ALONSO ORIO. Med. Esp. 51, 334-339 1964.

3 SACRISTAN DIAZ: Medicina 31, 137-141. 1963.

4 NAVARRO MARTINEZ P.: Med. Seg. Trab. 10, 39, 44-56. 1962.

5 ERRANDO VILAR, J.: Hip. Med. $1979 \quad 84$ 1962.

6 MARC HETTO, G.; BERTOLIN, A.: Attual, Ostet. Ginec. 7, 847-854. 1961.

7 PEÑA REGIDOR, P. DE LA: Clin. Lab. 68, 278-280. 1959.
8 DURAN CRESPO, A.: Rev. Españ. Obstet. Ginec. 18. 163, 168, 1959.

9 PICALlO, R.: Rev. Españ. Obst. Ginec. Valencia. 17, 219, 222. 1958.

10 FERRARI, B.: Quad. Clin. Obstet. Ginec. 13, 141, 150. 1958.

11 BRACO, G. MASSA, V.: Minerva Ginec. 12, 834-839. 1960 .

12 GORDILLO, J.: XIV Reunión Nal. de Ginec. Obst. de León. Gto. 1966. México.

13 CATAla DieZ, J.: Med. Esp. 55. 192. 199. 1966

14 MARIN NUÑEZ: Muench, Med. Esp. 108, 3. 210-214. 1966. 